\title{
From Particle Acceleration to Impact and Bonding in Cold Spraying
}

\author{
Tobias Schmidt, Hamid Assadi, Frank Gärtner, Horst Richter, Thorsten Stoltenhoff, \\ Heinrich Kreye, and Thomas Klassen
}

(Submitted February 11, 2009; in revised form May 29, 2009)

\begin{abstract}
In conventional thermal spraying, the spray particles are partially or fully molten when they deposit on the substrate. Cold spraying, in contrast, uses less thermal and more kinetic energy. In this process, solid particles impact on the substrate at high velocities and form excellent coatings. Due to comparatively low temperatures and typically inert process gases, cold spraying is particularly suitable for heat and oxidation sensitive materials. In recent years, modeling and computational methods have been widely used to study this relatively new spraying process, particularly to describe impact conditions of particles, to improve nozzle design, and to provide a better understanding of the thermo-mechanical processes that lead to particle bonding and deposition. This paper summarizes the state of the art in these theoretical studies, alongside a comprehensive description of the process. The paper also discusses the prediction of coating properties in the light of modeling combined with experimental investigations.
\end{abstract}

Keywords bonding mechanisms, cold gas spraying, deformation modeling, fluid dynamics, impact conditions, process optimization

\section{Introduction}

As a comparatively new powder spray technique, cold spraying is attracting a fast growing attention from the research community as well as from industries to explore its potentials for new applications. So far the matter has been the subject of an increasing number of publications, including a couple of textbooks (Ref 1-7). In contrast to conventional thermal spraying, deposition in cold spraying occurs without melting only by the deformation of solid particles. This can be realized due to high kinetic energies of the particles upon impact on the substrate (Ref 2, 3, 8-10). Figure 1 shows a sketch of the principle layout requested for cold spraying. A highly pressurized gas, typically nitrogen or helium, is preheated and then expanded in a converging, diverging De Laval type nozzle. Through a separate gas line, a fluidized powder feedstock is fed into or upstream of the nozzle. The powder is accelerated by the gas stream and impacts the substrate with high velocities. Depending on the choice of process gas (or gas mixtures) and the spray parameters, impact velocities between 200 and $1200 \mathrm{~m} / \mathrm{s}$ can be realized. The

Tobias Schmidt, Hamid Assadi, Frank Gärtner, Horst Richter, Thorsten Stoltenhoff, Heinrich Kreye, and Thomas Klassen, Helmut Schmidt University, Hamburg, Germany; Hamid Assadi, Tarbiat Modarres University, Tehran, Iran; Horst Richter, Thayer School of Engineering, Dartmouth College, Hanover, NH; and Thorsten Stoltenhoff, Praxair Surface Technologies, Ratingen, Germany. Contact e-mail: frank.gaertner@hsu-hh.de. particle temperature upon impact, also, depends on various factors-such as the gas temperature, nozzle design, and heat capacity of particles-and can be in the range between room temperature and $800{ }^{\circ} \mathrm{C}$.

The comparatively low process temperatures, the very short time scales and the use of more or less inert process gases make the cold spray process particularly suitable for applications where it is vital to avoid oxidation and to retain properties of the powder feedstock in the sprayed coatings (Ref 11). First industrial applications include, for instance, deposition of oxygen-free copper coatings where high electrical and thermal conductivity are critically required (Ref 12). Avoiding oxidation also diminishes crack nucleation and is thus beneficial for mechanical properties. As demonstrated for copper as spray material, yield strength and elongation to failure of cold-sprayed coatings can reach values comparable to highly deformed cold worked bulk material (Ref 13, 14).

In comparison to conventional thermal spraying, cold spraying has the additional advantage of being relatively simple to implement. The process control is carried out mainly through monitoring appropriate adjustment of gas pressures and temperatures. To optimize the process and to achieve best coating qualities, however, these parameters have to be finely tuned with respect to the spray material, powder size range and the nozzle type.

The simplicity of cold spraying also makes it a suitable subject for modeling. Thus, quite a number of attempts were made to describe the fluid dynamics of cold spraying (Ref 4, 9, 10, 15-17). Since the process gas is only electrically preheated, modeling does neither have to account for combustion, possible reaction products and effects on attainable temperatures and pressures, like in flame spraying (FS) and high velocity oxy-fuel flame spraying (HVOF), nor does it have to consider heat transfer and expansion of multicomponent gases in electrical discharges, as in plasma spraying (PS). Also, the particles are 
in the solid state and are barely oxidized as they hit the substrate, so that modeling of particle impact has to deal only with plastic deformation (Ref 18-21). Moreover, there are no complex effects due to solidification and accompanied shrinkage, or due to in-flight and postimpact oxidation of the spray material.

In summary, impact conditions and particle bonding of cold spraying can be modeled with quite high precision. Therefore, modeling can supply detailed information for process conditions of a particular spray material, i.e. process gas pressures and temperatures, and specific powder sizes and nozzle layouts. All that can be correlated to experimentally observed coating microstructures and properties. This comprehensive process analysis allows for very reliable cold spray design improvements for

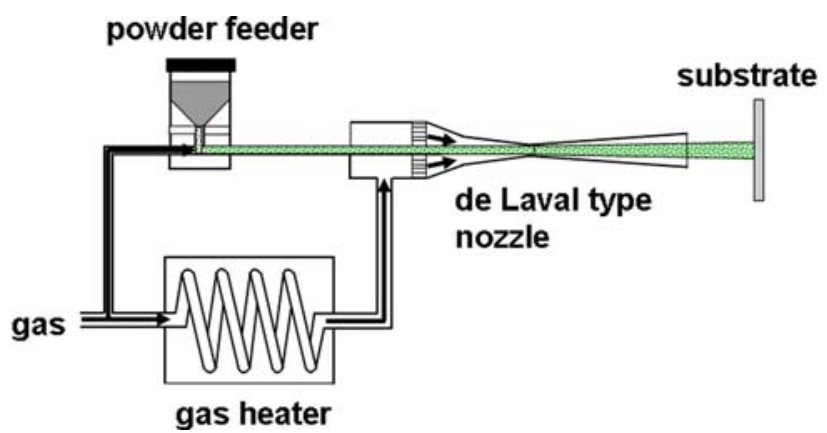

Fig. 1 Schematic of the cold spray technique commercially available equipment better than has been available for HVOF spraying or plasma spraying (PS).

The Fluent computational fluid dynamics code was employed to predict the particle properties, i.e. temperature and velocity at the point of impact on the substrate (Ref 22). The subsequent deformation of the particles was modeled by using the software package ABAQUS (Ref 23). The results of numerical modeling were assessed in light of various experiments and were subsequently summarized-where appropriate-into simple and easyto-use explicit formulae. This extensive modeling work permits to simplify the prediction of the performance of novel spray materials. Figure 2 illustrates the general concept of the modeling activities discussed in this paper.

\section{Fluid Dynamic Modeling of Cold Spraying}

In order to understand cold spraying and to realize optimum spray conditions, effects of process parameters and nozzle designs on particle impact conditions are needed. Thus, fluid dynamic modeling was employed to determine gas and particle temperatures and velocities. The calculations can describe the influences of nozzle geometry and all significant process parameters like the process gas, gas temperature and pressure, spray material type and particle size on particle impact conditions. Typically, as a first approach, an isentropic, one-dimensional model is used to calculate the Mach number, the gas

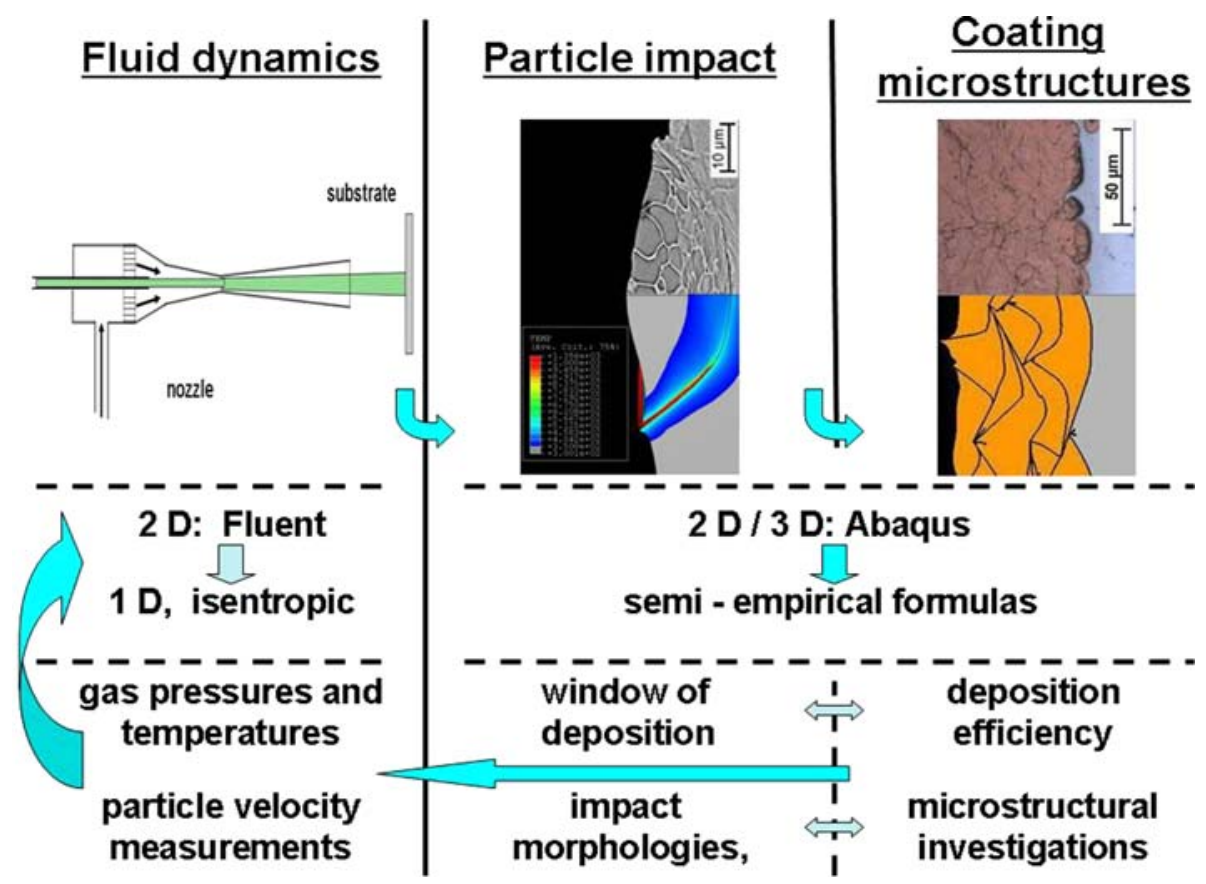

Fig. 2 Concept for the complete description of cold spraying by modeling and subsequent experimental verification. The concept describes a closed loop from impact conditions defined by fluid dynamics to bonding conditions and expected coating properties. The feedback by experimental investigations is used to improve impact conditions based on modeling. The divided insets show the modeled impact of copper on steel in detail, prospective coating formation and microstructural details 
velocity and all other properties of state for each cross section of the nozzle. In a second step, for such a set of given gas velocities and temperatures, particle acceleration and heat transfer can be calculated (Ref 9). In the heat transfer calculations, the thermal conductivity of the gas is approximated by the polynom from Eckert and Drake. The heat transfer to the particle is described by the Ranz-Marschall equation (Ref 9, 24, 25). Under typical spray conditions using particles with diameters of less than $100 \mu \mathrm{m}$, Biot numbers significantly smaller than 0.1 indicate that particle heating is dominated by the heat transfer to the particle and not the thermal diffusivity inside the particle (Ref 24, 25). This also demonstrates that the temperature distribution over the particle radius can be assumed as homogeneous during fluid dynamic calculations and for initial conditions in impact calculations (Ref 21, 25).

These one-dimensional flow calculations can only describe the gas-dynamic flow within the nozzle, and can only approximate the flow along the axis of a real threedimensional nozzle. More details of particle impact conditions can be supplied by employing a computational fluid dynamic code like FLUENT (Ref 22). Such finite volume two-phase flow analyses are used to gain information on velocities and temperatures over the whole cross section of the nozzle, to study the influence of intermixing with the environmental air in the free jet and to investigate the effects of the bow shock in front of the substrate. Results from modeling of fluid dynamics are crosschecked by experimental analysis of the particle velocity using a ColdSprayMeter system from TECNAR, Canada.

Experimental results show that observed particle velocities correspond quite well with those calculated by the finite volume method (Fluent), differing only about $\pm 10 \mathrm{~m} / \mathrm{s}$. Isentropic calculations neglect the interaction of the gas and the nozzle walls and in the free jet. For typical nozzle geometries, as for example trumpet-shaped nozzles (nozzle 2: Papyrin) or bell-shaped nozzles (nozzle 24: Stoltenhoff, MOC) and similar and for typical spray distances of 20 to $60 \mathrm{~mm}$, the isentropic calculations overestimate the particle velocities by $5-10 \%$. Reference values were calculated by using FLUENT and verified by velocity measurements. Thus, under these conditions, general trends can be easily derived from isentropic, onedimensional calculations. In case of nozzle concepts or spray conditions, which (i) are less adiabatic, (ii) cause thicker boundary layers, (iii) cause shocks inside or outside the nozzle and (iv) generate substantially disturbed free jets (intermixing with the environmental atmosphere or formation of bow shocks), isentropic calculations will not provide reliable data anymore.

A further source of error in calculating impact conditions could be given by the interaction of the injected particles with the super sonic jet. Under typical spray conditions, the volume ratio of powder in the gas stream is below $0.01 \%$ corresponding to a mass flow ratio of far less than $10 \%$. For a mass flow ratio of around $10 \%$, velocity measurements confirmed that particle velocities are decreased by about $5 \%$. From the small volume ratio, it can be concluded that particle-particle interactions are quite rare. Nevertheless, within the overall quite high number of traveling particles (several millions per second) some might show particle-particle or particle-wall interaction.

Apart from supplying a description of particle impact conditions, fluid dynamics can also be used to design nozzle geometries for optimum particle acceleration. Employing the so-called method of characteristics resulted in bell-shape nozzle contours, similar to that of rocket engines (Ref 24, 26). With this procedure, nozzles were developed that guarantee optimum and more homogeneous acceleration, avoid turbulences and thus energy losses inside the nozzle and even could reduce interactions with the environmental air by adjusting the exit pressure to the environmental pressure. In Fig. 3, the flow contours of a trumped-shaped nozzle (type 2: Papyrin) (Ref 2, 27) as used in early times of cold spraying, are compared to that obtained with an optimized design for the use of nitrogen as process gas to accelerate copper particles or

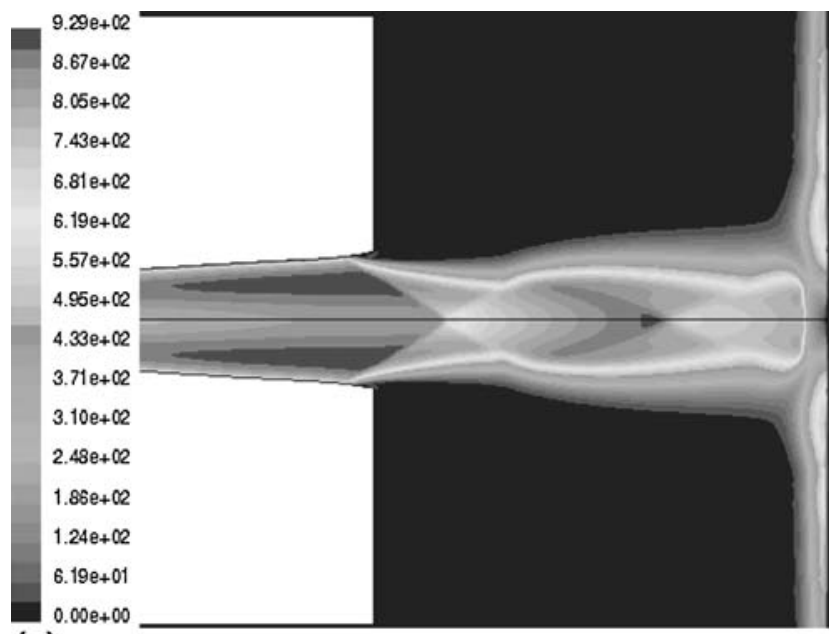

(a)

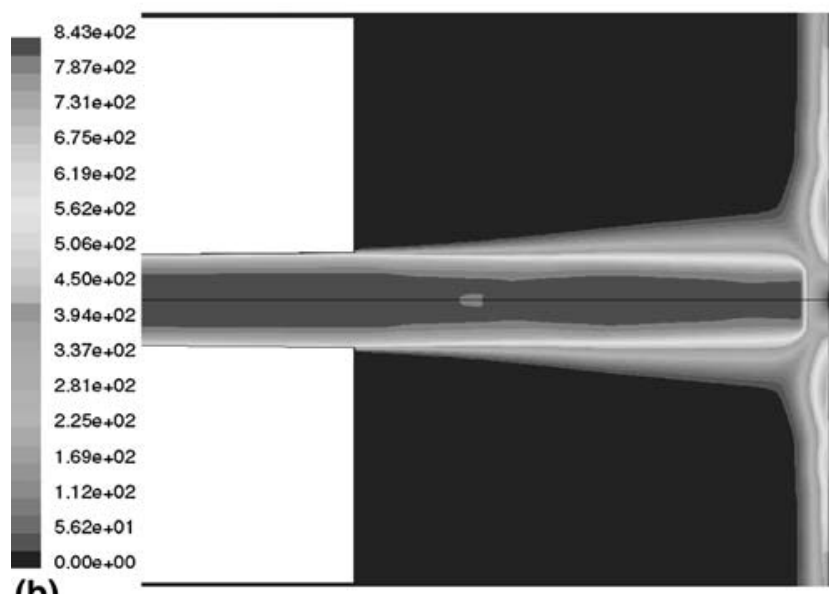

(b)

Fig. 3 Velocity contours of the free gas jets at exits of (a) a trumpet-shape nozzle and (b) a bell-shaped optimized nozzle design for nitrogen as process gas at a gas inlet pressure of 30 bars and a gas temperature of $320{ }^{\circ} \mathrm{C}$ (Fluent simulation) 
spray material of similar density (type 24: Stoltenhoff, MOC). With radial symmetry, the trumpet-like shape nozzle has a width of smallest cross section of $2.7 \mathrm{~mm}$, a length of the diverging section of $70 \mathrm{~mm}$ and an expansion ratio of 8.8. The overall gas consumption depends on process gas pressure, process temperature and mainly the width of the smallest cross section in the nozzle. In order to keep gas consumption of nitrogen below $100 \mathrm{~m}^{3} / \mathrm{h}$, the smallest cross section is kept at $2.7 \mathrm{~mm}$. For cold spraying copper and other feedstock powders of similar density with nitrogen as process gas, the bell-shape nozzle designed by the method of characteristics has a length of $130 \mathrm{~mm}$ of the diverging cross section and an expansion ratio of 5.8 (Ref 24,26$)$. The velocity contours demonstrate that the velocity distribution at the exit of the "MOC" nozzle is significantly more homogenous than that of the "trumpet shaped" nozzle. Moreover, the parallel gas stream of the bell-shape nozzle reduces intermixing with the surrounding atmosphere in the free jet, indicated by shock diamonds being less prominent. Both the more homogeneous velocity distribution and the higher gas velocities in the free jet contribute to more efficient particle acceleration. It should be noted that other spray materials and the use of other process gases like helium or process gas mixtures request other nozzle layouts. According to that the most influential parameter is the choice of process gas, resulting in different, optimum expansion ratios (Ref 24, 26).

Figure 4 shows the corresponding velocities for copper particles of different sizes for using nitrogen as process with a gas inlet pressure of 30 bars and gas temperature of $320{ }^{\circ} \mathrm{C}$. The comparison demonstrates that the bell-shaped nozzle geometry supplies significantly higher particle velocities than the trumpet-shaped nozzle. Using the bellshaped geometry, a copper particle with a diameter of $25 \mu \mathrm{m}$ will have an impact velocity of $525 \mathrm{~m} / \mathrm{s}, 75 \mathrm{~m} / \mathrm{s}$ faster than by using the trumpet-shaped nozzle. Apart from these findings, the calculated particle velocities also demonstrate that some particle acceleration also occurs in the free jet. Moreover, the calculations show the deceleration of small particle in the bow shock in front of the substrate. Particles with sizes smaller than $5 \mu \mathrm{m}$ will follow the gas stream like finest dust and either not impact on the substrate at all or are too slow for bonding.

The process gas achieves sound velocity in the smallest cross section of the nozzle. Since the velocity of sound is dependent on the gas temperature, raising the temperature would increase attainable gas and thus particle velocities. In addition, the higher gas temperatures will also result in higher particle impact temperatures. Based on less time consuming one-dimensional isentropic calculations, Fig. 5 shows the development of particle velocities and temperatures with increasing process gas temperatures for the example of the above-described bellshaped nozzle geometry and nitrogen as process gas. At a process gas pressure of 30 bars, increasing the gas inlet temperature from 300 to $900{ }^{\circ} \mathrm{C}$ will raise the velocity of a copper particle $25 \mu \mathrm{m}$ in size from $490 \mathrm{~m} / \mathrm{s}$ to about $620 \mathrm{~m} / \mathrm{s}$ (Ref 25). The particle temperature will be increased from about $70{ }^{\circ} \mathrm{C}$ to about $330^{\circ} \mathrm{C}$. The
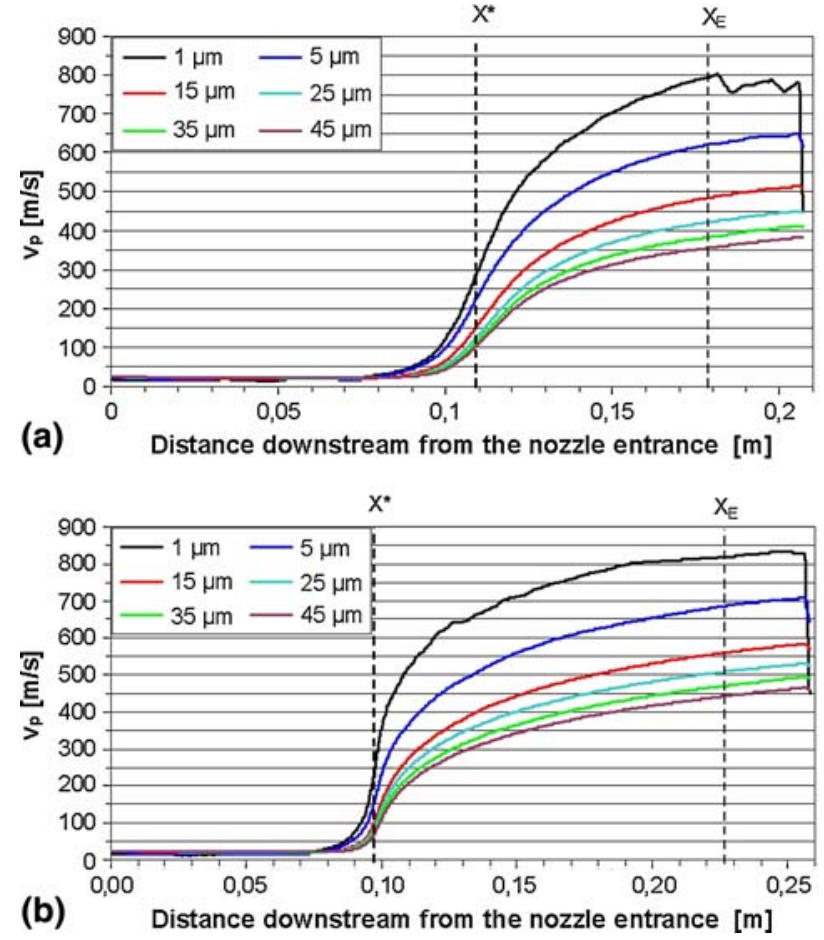

Fig. 4 Velocities of copper particles of different sizes along the nozzle axis and the free jet to the substrate; the calculations were performed for nitrogen as process gas at a gas inlet pressure of 30 bars and a gas temperature of $320{ }^{\circ} \mathrm{C}$ (Fluent simulation): (a) trumpet-shaped nozzle, (b) bell-shaped nozzle. $X^{*}$ and $X_{E}$ indicate the smallest cross sections and the nozzle exit (particles are injected $20 \mathrm{~mm}$ upstream of the smallest nozzle cross section)

calculations also show the influence of the process gas pressure on particle velocities and temperatures. A higher gas pressure corresponds to a higher gas density and thus could guarantee more effective particle acceleration. Increasing the pressure from 30 to 40 bars at a process gas temperature of $900{ }^{\circ} \mathrm{C}$ will increase the velocity of a copper particle $(25 \mu \mathrm{m}$ in size $)$ up to about $670 \mathrm{~m} / \mathrm{s}$. Under the so far assumed set-up, the particle temperature is only slightly affected by the gas pressure.

The bonding condition of an impacting particle is described by the overall particle energy. Thus, the influence of the particle temperature on the bonding must be evaluated (Ref 28-30). In cold spraying, particles heat up before the smallest cross section and cool down in the diverging section of the de Laval type nozzle. Thus, individual particle impact temperatures depend on the thermal history and on the thermal inertia of spray particles. As a result of isentropic modeling, Fig. 6(a) shows attainable gas and particle temperatures along the nozzle axis of a MOC nozzle with nitrogen as process gas ( $p_{\text {gas }}=40$ bars, $T_{\text {gas }}=900{ }^{\circ} \mathrm{C}$ ). Particles with a diameter of $5 \mu \mathrm{m}$, injected $20 \mathrm{~mm}$ upstream of the smallest nozzle cross section, attain nearly the gas temperature passing the smallest cross section. But due to their small size and low thermal inertia, they also cool down to temperatures of about $190{ }^{\circ} \mathrm{C}$, only $100{ }^{\circ} \mathrm{C}$ above process gas temperatures 

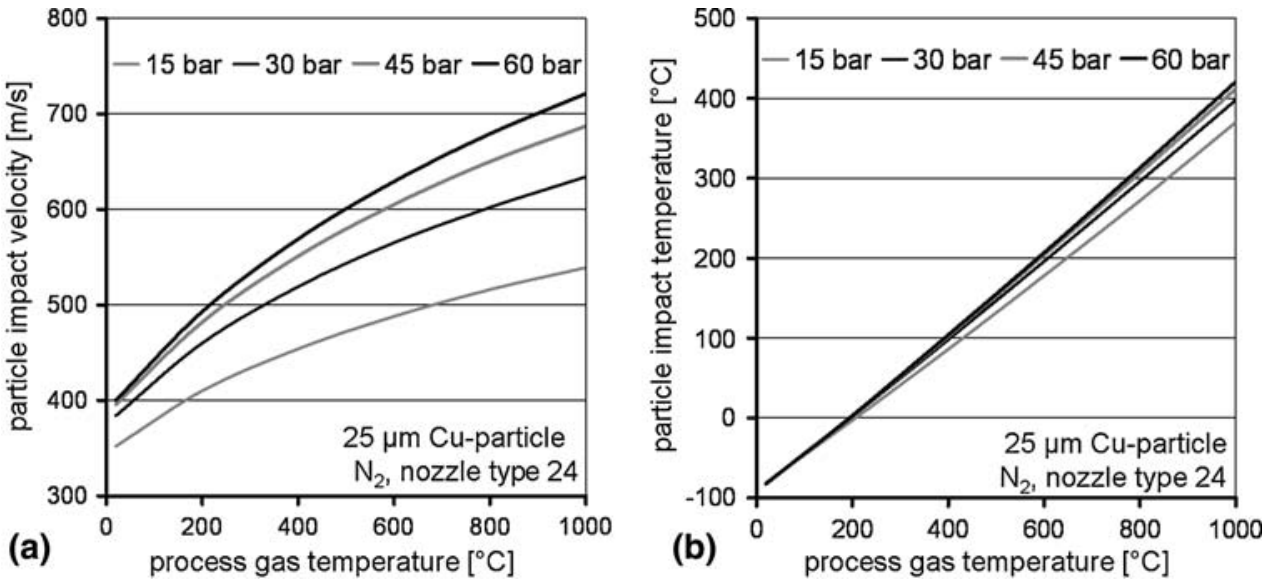

Fig. 5 Calculated copper particle impact velocities (a) and temperatures (b) for different temperatures and pressures of nitrogen as process gas (MOC-nozzle, particle injection $20 \mathrm{~mm}$ upstream of the smallest nozzle cross section, isentropic calculations)
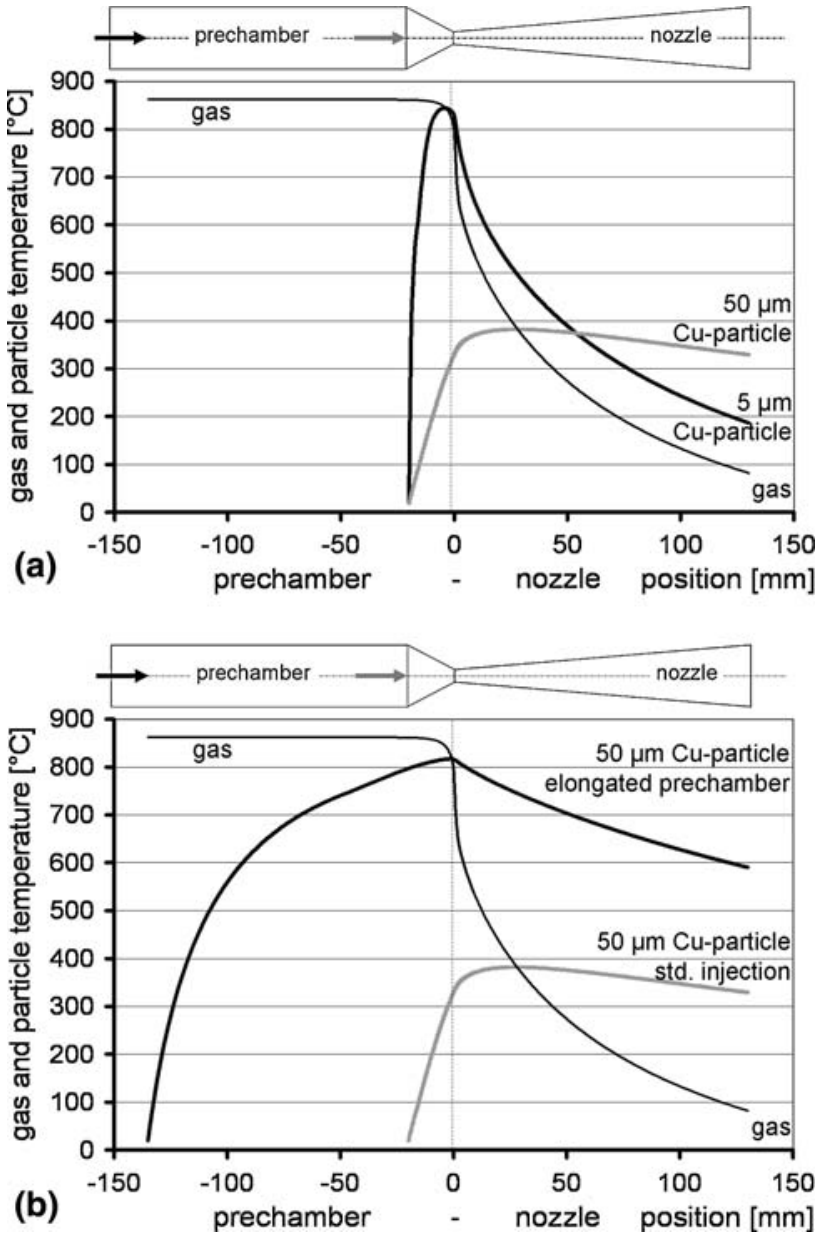

Fig. 6 Calculated copper particle temperatures during their flight though the nozzle (MOC-nozzle, nitrogen as process gas, $T_{\text {gas }}=900^{\circ} \mathrm{C}, p_{\text {gas }}=40$ bar, isentropic calculation). (a) The temperatures of copper particles with sizes of 5 and $50 \mu \mathrm{m}$ for particle injection $20 \mathrm{~mm}$ upstream of the smallest nozzle cross section. (b) The temperature of a copper particle with a size of $50 \mu \mathrm{m}$ for a particle injected $135 \mathrm{~mm}$ upstream of the smallest nozzle cross section during their flight through the diverging section of the nozzle. Bigger particles of $50 \mu \mathrm{m}$ in size are only slightly heated to about $380{ }^{\circ} \mathrm{C}$ before they pass the smallest cross section. Nevertheless, their thermal inertia is sufficiently high to leave the nozzle with a temperature of about $330^{\circ} \mathrm{C}$. Thus, it can be concluded that particle pre-heating can be beneficial for increasing particle impact temperatures and will be more effective for particles of larger size. Particle pre-heating can also be realized by direct heating of the fluidized powder feedstock gas line (Ref 29). Another option is to increase the residence time of particles in the hot gas stream upstream of the smallest cross section of the nozzle (Ref 14, 25, 28). As shown in Fig. 6(b), injecting copper particles with a size of $50 \mu \mathrm{m}$ at a distance of $135 \mathrm{~mm}$ upstream of the smallest cross section is sufficient for heating the particles almost to the process gas temperature. In the divergent section of the nozzle, particles with sufficient thermal inertia are only cooled down to a temperature of about $600{ }^{\circ} \mathrm{C}$. Temperatures of different size particles injected 135 and $20 \mathrm{~mm}$ upstream of the smallest cross section are illustrated in Fig. 7 with nitrogen as process gas $\left(p_{\text {gas }}=40\right.$ bars, $T_{\text {gas }}=$ $900{ }^{\circ} \mathrm{C}$ ). From the diagram it can be concluded that copper particles with sizes between 50 and $70 \mu \mathrm{m}$ retain highest temperatures upon impact.

In conclusion, for cold spraying, fluid dynamics can supply information on the most influential parameters for particle impact conditions, such as particle impact velocities and temperatures. This knowledge is advantageous to request specific powder size fraction distribution for certain coating tasks. The consequences for particle bonding and coating properties are discussed in the following sections.

\section{Particle Bonding}

The most important criterion in cold spray is that material deposition takes place only if the impact velocity of the 
particles on the substrate exceeds a certain material dependent value-the so-called critical velocity. Figure 8 schematically shows the materials deposition efficiency (DE)

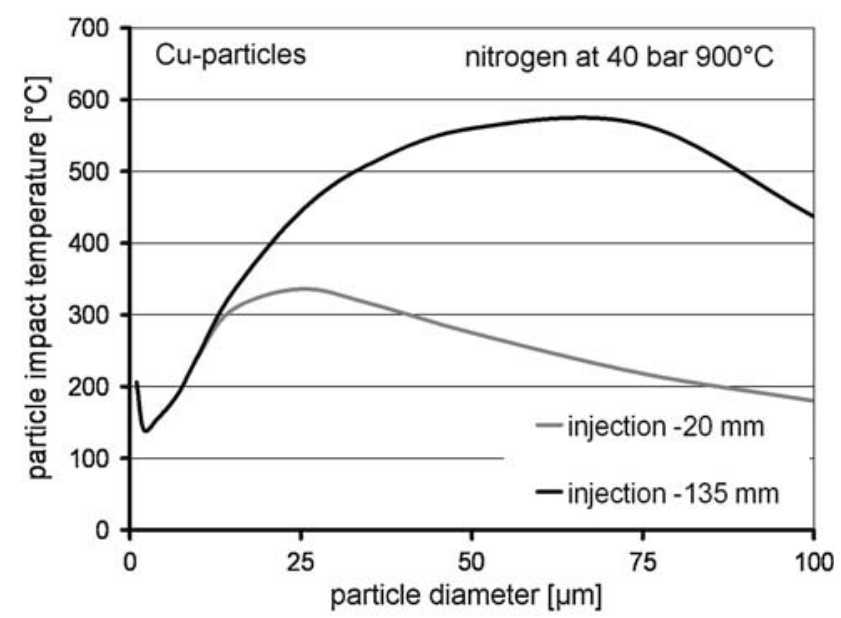

Fig. 7 Calculated copper particle impact temperatures of different particle sizes for particle injection $20 \mathrm{~mm}$ and 135 upstream of the smallest cross section (MOC-nozzle, nitrogen as process gas, $T_{\text {gas }}=900^{\circ} \mathrm{C}, p_{\text {gas }}=40$ bar, isentropic calculation) as a function of impact velocity for a certain impact temperature. In case of a material with an ideal ductility at a certain velocity depositions starts to occur. A further increase of velocity leads to a steep increase in DE, finally leveling off in saturation close to $100 \%$. At $50 \%$ DE, the critical velocity is defined (vertical green line in Fig. 8). In the region where the DE reaches saturation, optimum coating conditions can be expected. After reaching the saturation limit, the DE decreases with further increase in particle velocity due because of erosive effects due to hydrodynamic penetration of the substrate by the particles. This phenomenon is known from large-scale impact dynamics and can also be applied to cold spraying (Ref 21). Cross sections of large-scale impacts $(20 \mathrm{~mm} \mathrm{Cu}$ balls on steel substrates) are shown to elucidate the respective phenomena. At the velocity where the deposition changes to erosion $(0 \% \mathrm{DE})$, the erosion velocity is defined. For most materials this velocity is two or three times higher than the critical velocity. Brittle materials like ceramics would cause erosion for any velocity at temperatures below their melting temperature.

The critical particle velocity for bonding, $v_{\text {crit }}$, depends on various factors, but most prominently on the properties of the spray material. Table 1 shows the experimentally evaluated values of critical velocity for various metallic materials. Note that the critical velocity does not correlate

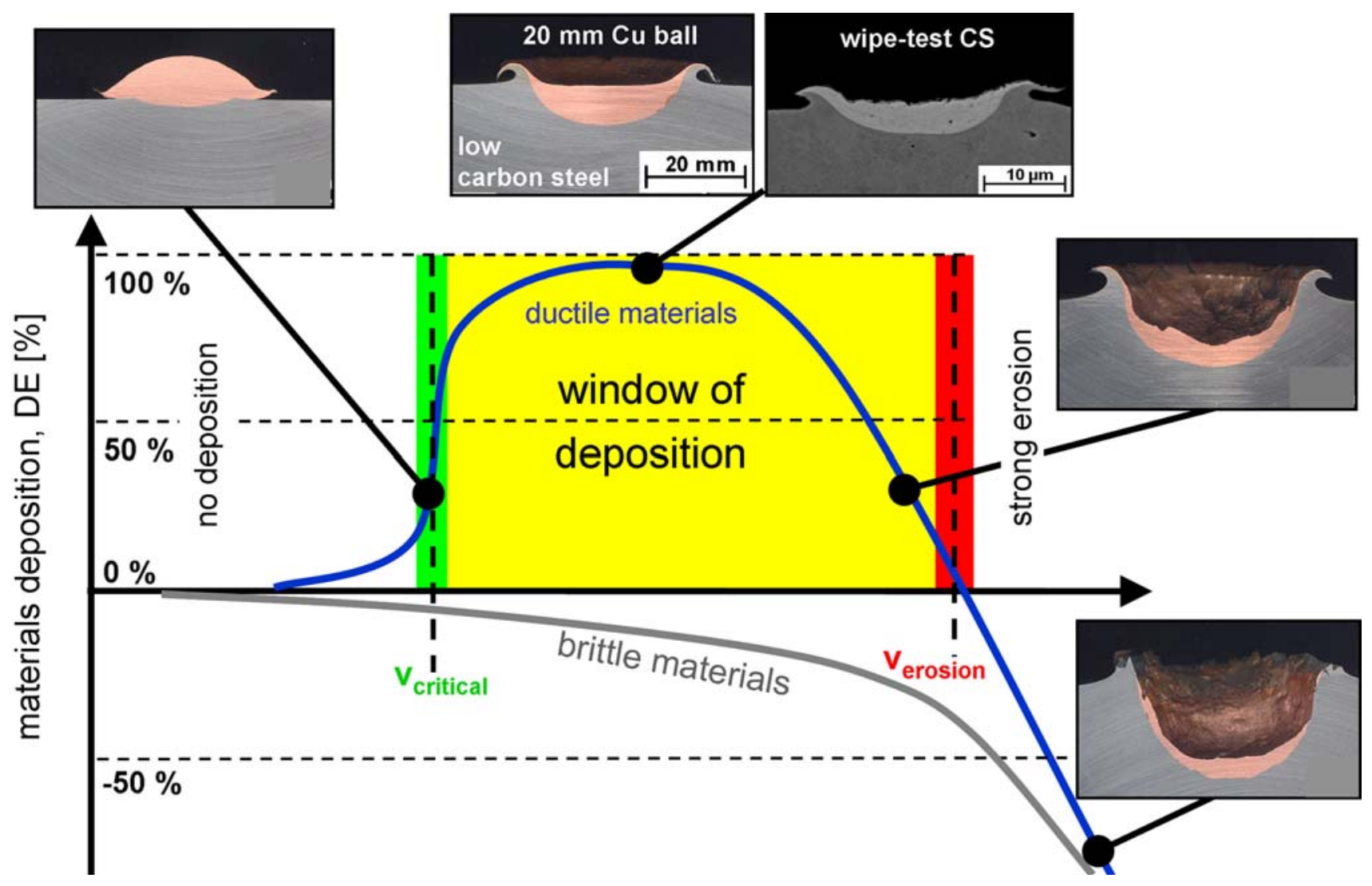

Fig. 8 Schematic correlation between particle velocity, deposition efficiency (DE) and impact effects for a constant impact temperature. Deposition is only observed for ductile materials in a certain velocity range for a given powder size and temperature, the so-called "window of deposition" 
Table 1 Values of critical velocity for bonding assuming a particle size of $20 \mu \mathrm{m}$

\begin{tabular}{lcc}
\hline Material & Melting point, ${ }^{\circ} \mathbf{C}$ & Critical velocity, m/s \\
\hline Aluminium & 660 & $620-660$ \\
Titanium & 1670 & $700-890$ \\
Tin & 232 & $160-180$ \\
Zinc & 420 & $360-380$ \\
Stainless steel (316L) & 1400 & $700-750$ \\
Copper & 1084 & $460-500$ \\
Nickel & 1455 & $610-680$ \\
Tantalum & 2996 & $490-650$ \\
\hline
\end{tabular}

with the melting temperature alone-compare, for instance, aluminum with tantalum.

The correlation between material properties and the critical velocity is rather an outcome of the interplay between the kinetic energy, the material strength, and the heat generation due to plastic deformation. Based on a detailed analysis of this interplay (Ref 21), the critical velocity can be expressed as a function of material properties and the materials temperature just before impact

$v_{\text {crit }}=\sqrt{A \sigma / \rho+B c_{\mathrm{p}}\left(T_{\mathrm{m}}-T\right)}$

where $\sigma$ is the temperature-dependent flow stress, $\rho$ is the density, $c_{\mathrm{p}}$ is the heat capacity, $T_{\mathrm{m}}$ is the melting temperature, $T$ is the mean temperature of particles upon impact, and $A$ and $B$ are fitting constants. This simple equation assumes same material and same material temperature for spray material and substrate. The best correlation with the experimental data is obtained when $A=4$ and $B=0.25$. The temperature-dependent flow stress can approximately be calculated by $\mathrm{Eq} 2$, where $T_{\mathrm{R}}$ is the temperature at which the ultimate strength was determined (usually $20^{\circ} \mathrm{C}$ ). The equation assumes a linear softening of the material toward the melting temperature, which in context with Eq 1 gives a strong temperature dependence of the critical velocity.

$\sigma=\sigma_{\text {ultimate }}\left[1-\frac{T-T_{\mathrm{R}}}{T_{\mathrm{m}}-T_{\mathrm{R}}}\right]$

With respect to the approximation of the critical velocity with $\mathrm{Eq} 1$, it must be noted that mechanical properties of powders could differ from that of bulk material. For a more precise prediction of requested spray conditions for bonding, mechanical properties of the spray powder must be determined. Hardness measurements at powder cross sections offer one possible option to get a more reliable forecast of the critical velocity.

It is also interesting to note that the kinetic energy corresponding to the critical velocity for bonding is much below that required for heating and complete melting of the particle due to plastic dissipation. The latter velocity, $v_{\mathrm{m}}$, can be worked out by considering the following simple energy-balance relationship.

$c_{\mathrm{p}}\left(T_{\mathrm{m}}-T\right)+L=\frac{1}{2} v_{\mathrm{m}}^{2}$

in which $L$ is the latent heat of fusion. As shown in Fig. 9, the critical velocity is approximately half of the velocity required to cause complete melting of the particle under the assumption of $T=25^{\circ} \mathrm{C}$ as impact temperature. This means that the kinetic energy required for bonding is not nearly sufficient for melting of an impinging particle.

A few questions naturally arise with respect to the above observations: What exactly happens at or beyond the critical velocity, particularly near the interacting surfaces? What is the nature of the phenomena that lead to bonding? Where exactly does the bonding initiate, and how does the bonded area develop, e.g. with increasing the kinetic energy? Does melting play a key role in particle deposition?

In order to obtain an insight into the mechanism of bonding, the impact of particles has been modeled by using the finite element program ABAQUS/Explicit (Ref 23). Details of the modeling procedure have been explained elsewhere (Ref 19, 21). The model takes into account the effects of strain, strain rate and temperature on the flow stress of the material. Although initial studies assumed adiabatic heating, more recent analysis included diffusive heat conduction, which is necessary when exploring the effect of the particle size on critical velocity and bonding. For most cases of analysis, axisymmetric models were used to simulate perpendicular impacts of copper particles on copper substrates, as shown in Fig. 10.

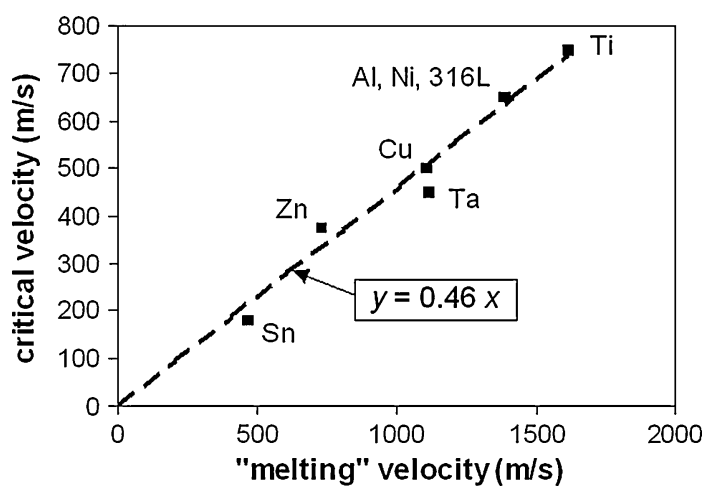

Fig. 9 Correlation between the critical velocity of bonding and that required for complete melting of a particle

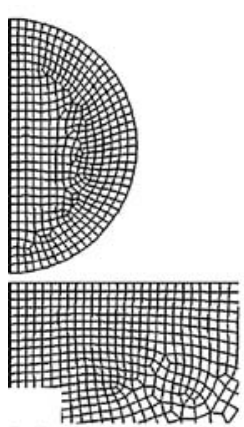

(a)

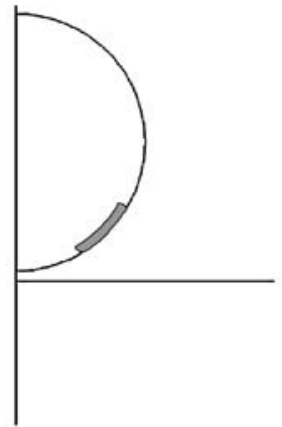

(b)

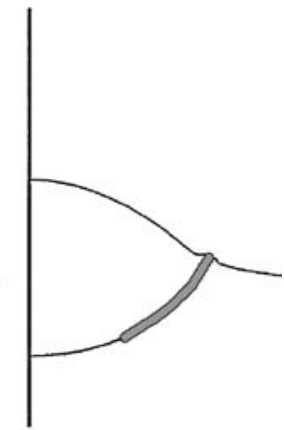

(c)
Fig. 10 Axisymmetric model of particle impact, showing (a) the initial mesh, and the monitored element set (dark ribbon) in the (b) un-deformed and (c) deformed states 
A common feature in all simulations is that there is markedly inhomogeneous deformation of particles and localized heating of the interacting surfaces as a result of impact. The temperature change at the contact surface of particles is shown in Fig. 11 and 12. As shown in the Fig. 12, for sufficiently large particles, there is a sudden temperature rise in the monitored element set (marked in Fig. 10) when the impact velocity is beyond $400 \mathrm{~m} / \mathrm{s}$. This temperature rise is an indication of the shear instability, which causes extensive flow of material at the corresponding surfaces. Here the important finding is that the estimated impact velocity to induce shear instability compares fairly well with the experimentally determined critical velocity of copper. This means that, as in the case of explosive welding of materials, bonding in cold spray is a result of the shear instability at the interacting surfaces.

Figure 13 summarizes impact calculations performed for 5, 15, 25, 50 and $150 \mu \mathrm{m} \mathrm{Cu}$ particles, where the impact velocity was varied in $50 \mathrm{~m} / \mathrm{s}$ steps from 300 to $600 \mathrm{~m} / \mathrm{s}$. The initial temperature of particles and the substrate material was constant at $20{ }^{\circ} \mathrm{C}$. This diagram shows the maximum interface temperature (compare Fig. 12) of the monitored element set (compare Fig. 10) as a function of the impact temperature for the different particle sizes. The more or less steep rise in interface temperature indicates the occurrence of shear instabilities. Assuming that bonding needs a minimum interface temperature of $60 \%$ of the melting temperature in $\mathrm{K}$, for the different particle
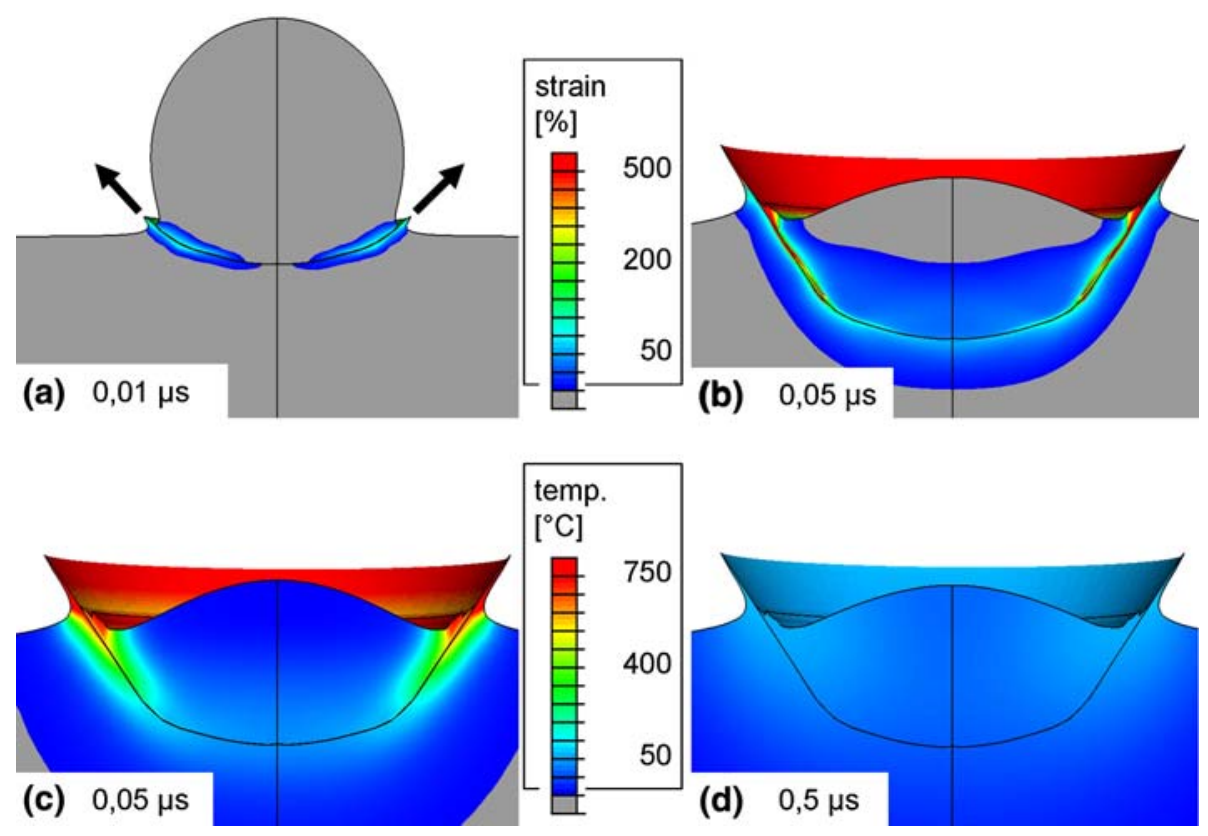

Fig. 11 Single sequences of an impact of a $25 \mu \mathrm{m} \mathrm{Cu}$ particle to a $\mathrm{Cu}$ substrate with $500 \mathrm{~m} / \mathrm{s}$ at an initial temperature of $20{ }^{\circ} \mathrm{C}$. (a, b) Strain field and (c, d) temperature field. For the analysis a thermally coupled axisymmetric model was used
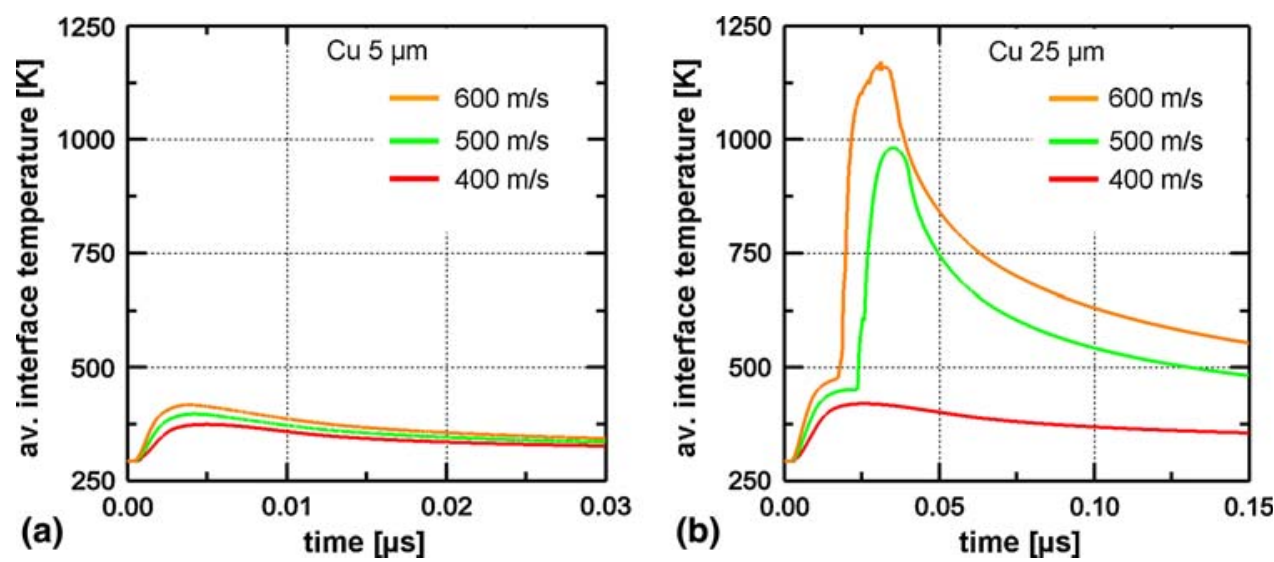

Fig. 12 Temporal evolution of the temperature at the monitored element set (dark ribbon in Fig. 10) for different velocities and particle sizes of (a) $5 \mu \mathrm{m}$ and (b) $25 \mu \mathrm{m}$ 


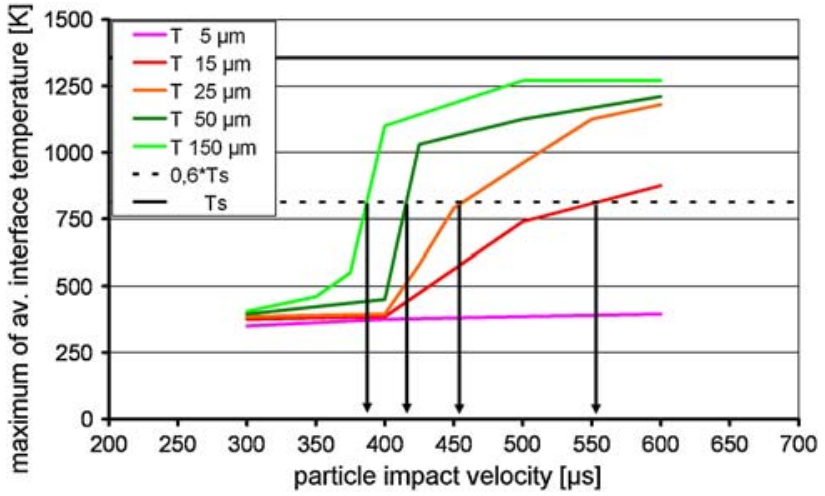

Fig. 13 Maximum interface temperature (compare Fig. 11) at the monitored element (compare Fig. 10) set as a function of impact temperature, plotted for different particle sizes

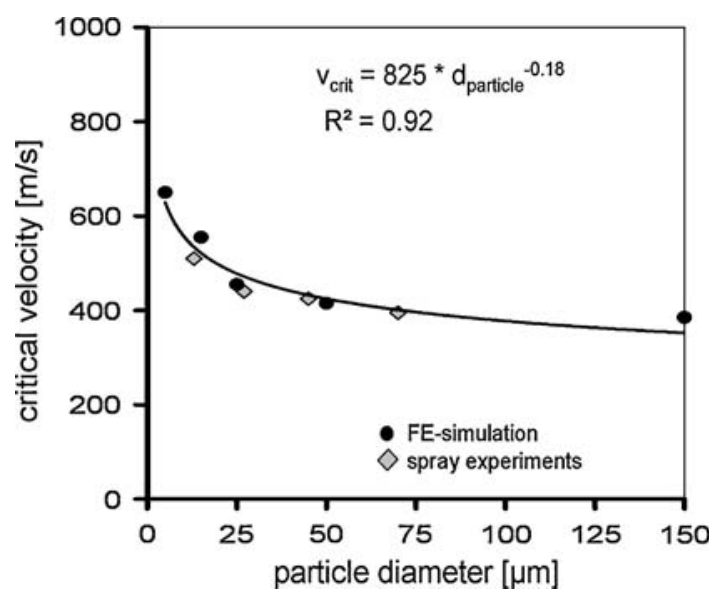

Fig. 14 Critical velocities of copper particles as a function of their diameter. The results from modelling and experiments originate from investigating (modelling, experiments) batches of different powder sizes. All results are standardized for an impact at room temperature

sizes different critical velocities can be determined, indicated by the vertical arrows toward velocity axis. The critical velocities determined in this way are plotted in Fig. 14.

The results of modeling illustrate the effect of particle size on the deformation scenario and are in consistence with the experimental data. Consequently, better interparticle bonding is achieved and expressed by higher cohesive strength of the coatings with increasing particle size. As a rough approximation based on simulation and experimental results, the critical velocity of $\mathrm{Cu}$ can be given as a function of impact temperature $T_{\mathrm{p}}$ and particle diameter $d_{\mathrm{p}}$ :

$\nu_{\text {crit }}\left(d_{\mathrm{p}}, T_{\mathrm{p}}\right)=\frac{\sqrt{657000-600 * T_{\mathrm{p}}}}{d_{\mathrm{p}}^{0.18}}$

The modeling work has been complemented by experimental studies of the interaction of the individual particles with the substrate. Single impacts during spray experiments can be produced by the so-called wipe tests, in which a polished substrate is moved rapidly through the spray jet. Subsequently, SEM can be used to investigate the morphology of particle/substrate interactions. The wipe test also allows investigation of angular impactsproduced by tilting the substrate to a desired angle. Figure 15 shows SEM micrographs corresponding to these tests, as obtained for two different spraying angles. The top-left micrograph shows a back-scattered electron image of a crater created on a steel substrate, as a result of a perpendicular impact of a copper particle. The particle has evidently bounced back or detached from the substrate after impact, possibly because of the spring-back forces, or because of being eroded away by the impact of subsequent particles. The arrows point to traces of copper that are left at the rim of the crater, here denoted by a dashed circle. These traces show that partial bonding of the particle had occurred during the impact, but presumably the fraction of bonded area was too small to withstand the back-spring tensile forces. Such traces of copper at the rim of some of the craters also show clearly that bonding of particles to the substrate occurs initially at the edge of the contact surfaces. This result is in a remarkable agreement with the results of modeling, with respect to the mechanism of bonding as well as the location of shear instability (Fig. 15, top-right inset). The bottom-left micrograph gives a different account of particle/substrate interaction, for a case where the impact has not been perpendicular. In an angular impact, an additional temperature rise can occur at the interface due to frictional dissipation, which could facilitate the occurrence of shear instability. The frictional dissipation can additionally shift the location of shear instability toward the "south pole" of the particle. This effect would obviously be more prominent for impacts with smaller angles, i.e. those farther away from perpendicular conditions. However, the tangential component of the momentum of the particle in an angular impact creates a tensile force at the interface, which could be large enough to detach the particle from the substrate. As shown in the bottom-right inset, the location of shear instability in an angular impact can also be illustrated by modeling.

\section{Prediction of Coating Properties}

The previous sections focused on the bonding mechanisms upon impact and the dependence of impact parameters on process parameters. This section concentrates on the influence of the impact conditions on coating properties. Respective fluid dynamics calculations and impact simulations will be correlated to experimental results for particular powder feedstock characteristics.

The impact simulations presented in the previous section can be extended to predict microstructures of a coating, as shown in Fig. 16 for different materials. Depending on the process parameters and material properties, different degrees of deformation and resulting 

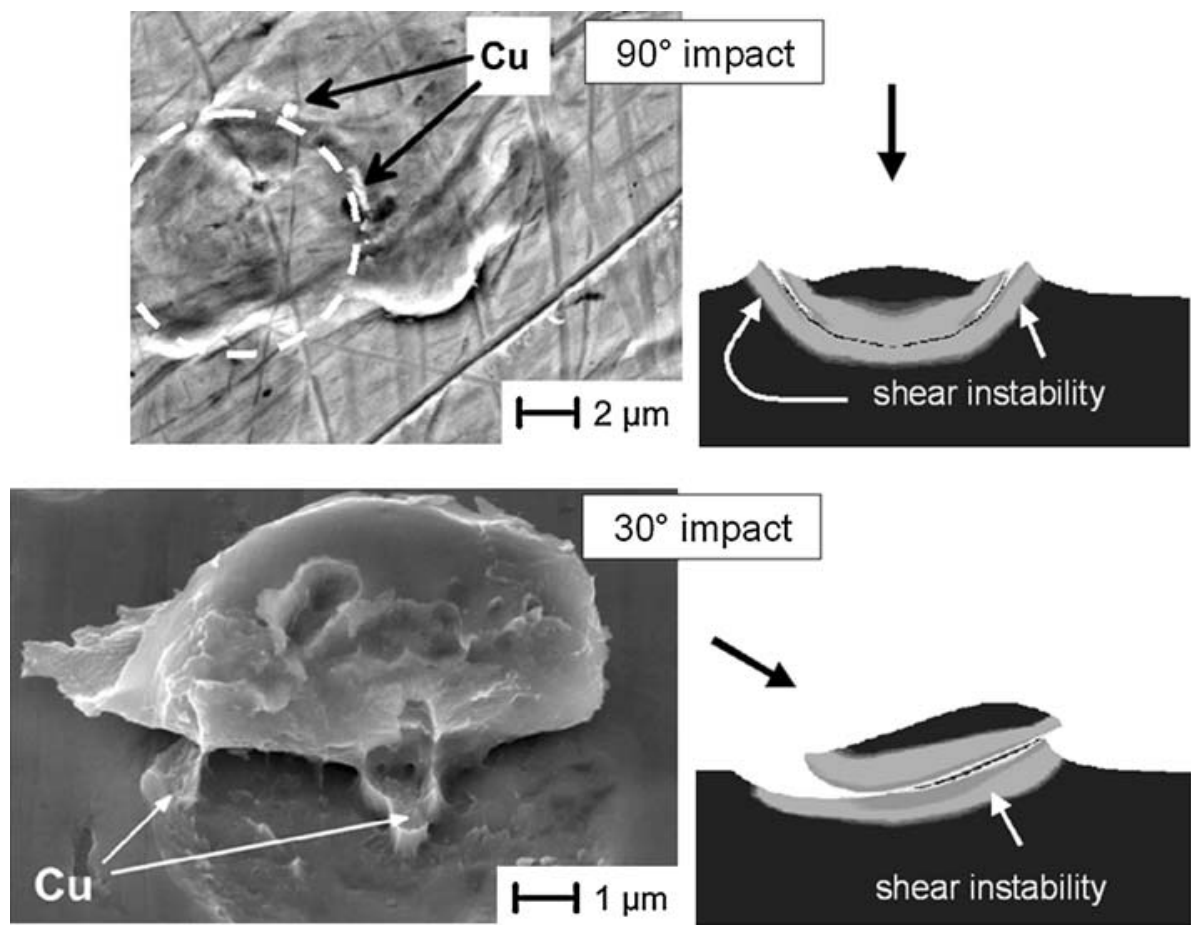

Fig. 15 Location of shear instability in perpendicular and angular impacts
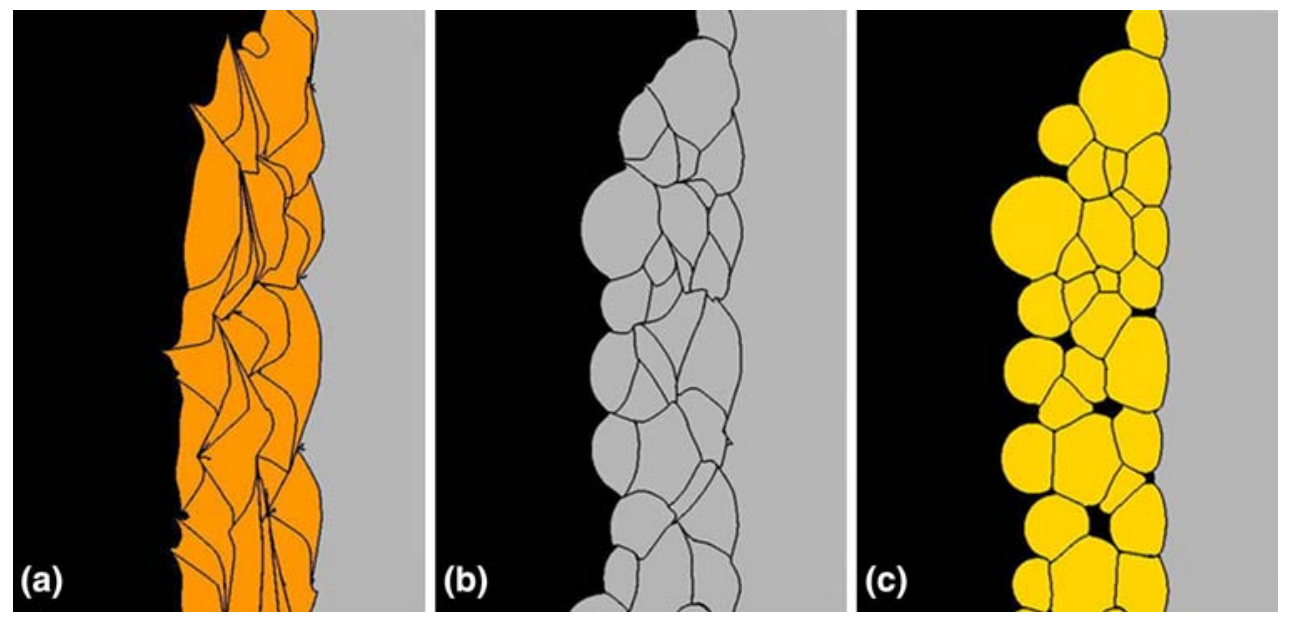

Fig. 16 2D simulation of a multi impact scenario calculated for different material combinations under identical impact conditions. The initial impact temperature was set to $20^{\circ} \mathrm{C}$ and particle impact velocities ranged between 400 and $650 \mathrm{~m} / \mathrm{s}$ depending on particle diameters. Particle sizes were varied in range between 8 and $50 \mu \mathrm{m}$. (a) Cu on steel 316L, (b) steel 316L on steel 316L, and (c) Ti-6Al-4V on steel $316 \mathrm{~L}$

porosities can be predicted. However, even more important is the prediction of mechanical properties of the coatings based on the respective extent of plastic deformation and occurring shear instabilities.

To highlight differences in attainable microstructures and mechanical properties, this study focuses in detail on three process parameter settings. These settings can be attributed to distinct development steps $\left(2,5^{*}\right.$ and 5$)$ in cold spraying, which are shown in Table 2. Table 2 also contains experimentally obtained key data of coating properties, sprayed with the listed nozzle, gas, and upstream gas conditions. The first setting is the previous standard parameter for cold spraying of copper with a MOC nozzle, as implemented in 2003 (development step 2 ) and serves as a reference. The second parameter setting represents the optimized condition for cold spraying of copper, by using the "Activejet" spray gun together with a MOC nozzle and nitrogen at 30 bars and $800{ }^{\circ} \mathrm{C}$ as process 
Table 2 Development steps in cold spraying with corresponding spray parameter sets and experimentally determined properties of respective coatings

\begin{tabular}{|c|c|c|}
\hline Year & Step & Step description \\
\hline 2001 & 1 & $\begin{array}{l}\text { Trumpet-shaped steel nozzle, } \mathrm{N}_{2} 30 \text { bar } 300^{\circ} \mathrm{C} \text {, injection } 25 \mathrm{~mm} \text { upstream throat } \\
\mathrm{Cu}-25+5: \mathrm{DE} \sim 60 \% \text {, TCT strength } \sim 50 \mathrm{MPa} \text {, electrical conductivity up to } 55 \%\end{array}$ \\
\hline 2003 & 2 & $\begin{array}{l}\text { MOC (bell-shaped) steel nozzle, } \mathrm{N}_{2} 30 \text { bar } 300{ }^{\circ} \mathrm{C} \text {, injection } 25 \mathrm{~mm} \text { upstream throat } \\
\mathrm{Cu}-25+5: \mathrm{DE} \sim 80 \% \text {, TCT strength } \sim 60 \mathrm{MPa} \text {, electrical conductivity up to } 60 \%\end{array}$ \\
\hline 2004 & 3 & $\begin{array}{l}\text { MOC (bell-shaped) WC-Co nozzle, } \mathrm{N}_{2} 30 \mathrm{bar} 600{ }^{\circ} \mathrm{C} \text {, injection } 25 \mathrm{~mm} \text { upstream throat } \\
\mathrm{Cu}-38+11: \mathrm{DE}>95 \% \text {, TCT strength } \sim 110 \mathrm{MPa} \text {, electrical conductivity up to } 75 \%\end{array}$ \\
\hline 2006 & 4 & $\begin{array}{l}\text { MOC (bell-shaped) WC-Co nozzle, } \mathrm{N}_{2} 30 \text { bar } 600{ }^{\circ} \mathrm{C} \text {, injection } 135 \mathrm{~mm} \text { upstream throat } \\
\mathrm{Cu}-38+16: \mathrm{DE}>95 \% \text {, TCT strength } 160 \mathrm{MPa} \text {, electrical conductivity up to } 80 \%\end{array}$ \\
\hline 2006 & $5^{*}$ & $\begin{array}{l}\text { MOC (bell-shaped) WC-Co nozzle, new gun, } \mathrm{N}_{2} 30 \text { bar } 800{ }^{\circ} \mathrm{C} \text {, injection } 135 \mathrm{~mm} \text { upstream throat } \\
\mathrm{Cu}-38+16: \mathrm{DE}>95 \% \text {, TCT strength } \sim 250 \mathrm{MPa} \text {, electrical conductivity up to } 90 \%\end{array}$ \\
\hline 2006 & 5 & $\begin{array}{l}\text { MOC (bell-shaped) WC-Co nozzle, new gun, } \mathrm{N}_{2} 40 \text { bar } 900^{\circ} \mathrm{C} \text {, injection } 135 \mathrm{~mm} \text { upstream throat } \\
\mathrm{Cu}-75+25: \mathrm{DE}>95 \% \text {, TCT strength } \sim 300 \mathrm{MPa} \text {, electrical conductivity up to } 95 \%\end{array}$ \\
\hline
\end{tabular}

The term "new gun" denotes the in-house development of the spray configuration allowing higher process temperatures by an additional filament heater. The coatings strengths according the mentioned TCT-data must multiplied with a factor of 1.5 to correlate with tensile strengths. It should be noted that the electrical conductivity strongly depends on the chemical composition of the powder; see *. The electrical conductivity refers to the IACS standard, which is set to $100 \%$
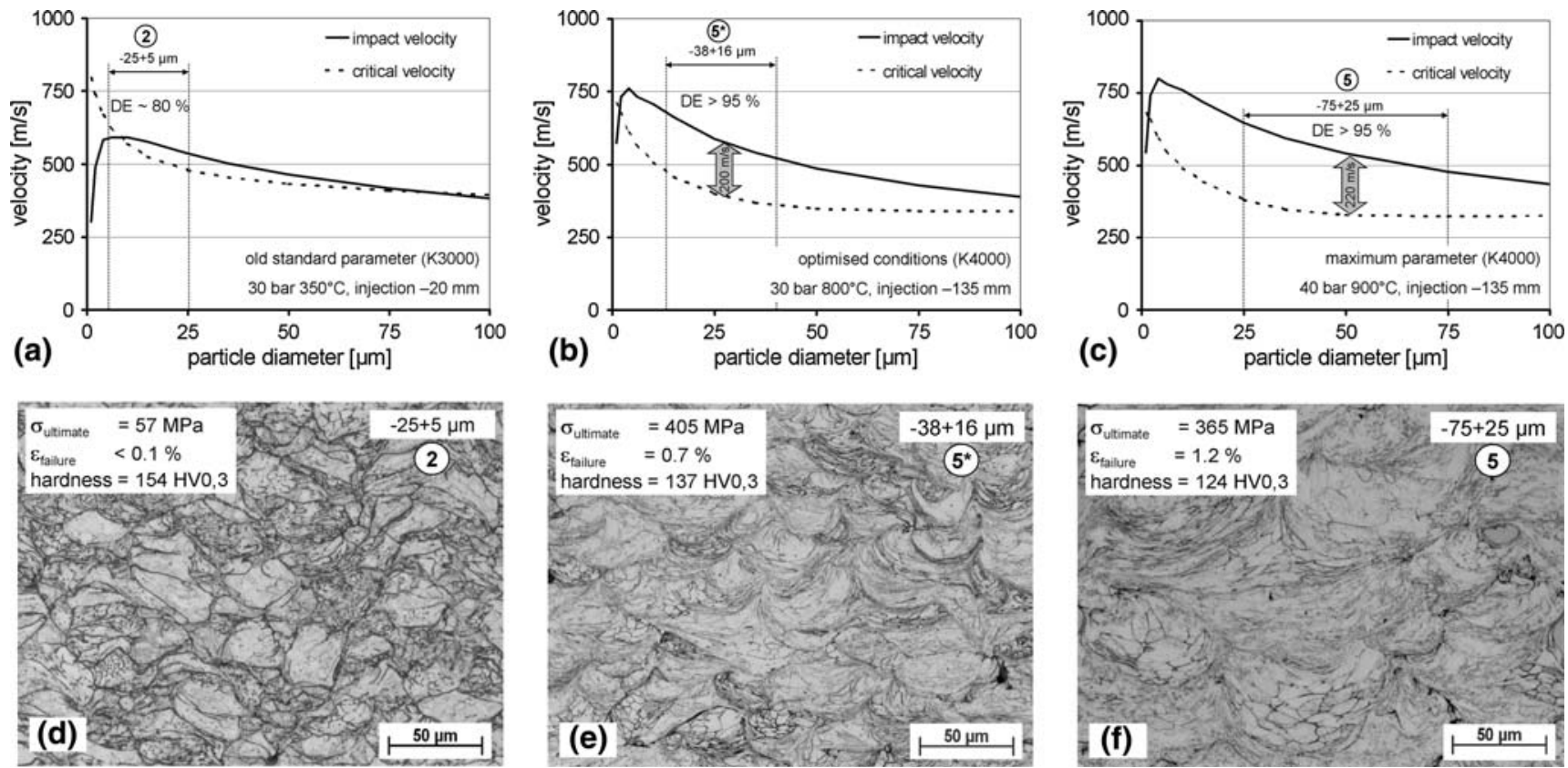

Fig. 17 (a-c) Impact and critical velocities (including the effect of impact temperature) as a function of particle diameter calculated for the used process conditions. The used size distribution is marked in each diagram. For the high end parameter settings $5^{*}$ and 5 , the impact velocity is exceeding the critical velocity by more than $200 \mathrm{~m} / \mathrm{s}$ (vertical arrow). The experimentally determined deposition efficiency DE is also shown in the diagram. (d-f) Etched coating microstructures and experimentally determined mechanical properties for parameter sets $(a-c)$

gas (development step 5*, between 4 and 5). The particles of the $-38+16 \mu \mathrm{m} \mathrm{Cu}$ powder are injected $135 \mathrm{~mm}$ upstream of the nozzle throat. The third parameter setting represents the maximum available process conditions for the spray gun Kinetiks 4000 (development step 5) at 40 bars nitrogen pressure and a temperature of $900{ }^{\circ} \mathrm{C}$, enabling the use of a very coarse size distribution $(-75+25 \mu \mathrm{m})$. The powder was injected $135 \mathrm{~mm}$ upstream of the nozzle throat.

All particle velocities and particle temperatures used in this study are determined by gas dynamic calculations.
The gas expansion in the nozzle is assumed to be isentropic in these calculations. The effect of the free jet, including the bow shock in front of the substrate on the impact conditions of the particles is implemented by a simple but realistic approximation.

The calculated critical velocities and calculated particle impact velocities of the three chosen parameter settings (development step 2, 5* and 5) are shown in Fig. 17(a)-(c). For the calculation of the critical velocity, the particle impact temperature was considered, which depends on the particle size and spraying parameters. Comparing 
Fig. 17(a), (b) and (c) for respective size distributions, the significant larger range between the impact velocity and the critical velocity demonstrates that significantly better coating qualities should be obtained under enhanced process conditions, according to step $5^{*}$ and 5 in Fig. 17(b) and (c). Experimental results on coating microstructures and properties confirm the results from modeling. Figure 17(d)-(f) shows the etched cross sections of copper coatings obtained by the three parameter settings and as inserts experimentally observed coating properties. The etched microstructure of the coating sprayed under the development step 2 conditions (Fig. 17d) is dense, but shows that particle-particle interfaces are more revealed by etching than those of the coatings sprayed under development step $5^{*}$ conditions (Fig. 17e) and under development step 5 conditions (Fig. 17f). Under step $5^{*}$ and step 5 conditions, most particle-particle boundaries show a similar contrast as the normal grain boundaries, indicating similar chemical stabilities and tight bonds.

Even at the parameter settings working with higher gas temperatures, the oxygen content of the coatings was very low (0.03-0.05 wt.\%). The electrical conductivity of the coatings in the as-sprayed condition was increased from $60 \%$ for the step 2 condition to almost $80 \%$ in the step 5* condition, taking annealed bulk copper as a reference (IACS value is $100 \%$ ) (Ref 14). In the case of very pure powder, even $90 \%$ of the IACS value in the as-sprayed state and $95 \%$ in the annealed condition can be reached. Under step 2 condition, a coating hardness of 155 HV0.3 was obtained, whereas under step $5 *$ conditions the coating reached $137 \mathrm{HV} 0.3$ and under step 5 conditions 125 HV0.3. The lower hardness can be explained due to the thermal treatment of the coating by the hot gas stream as well as by the higher particle impact temperature and the lower particle impact velocity of the coarser particles.

So far, a range of maximum changes was described by comparing sets of development step 2, $5^{*}$ and 5 conditions. Experimental results of gradual changes between these fix points are illustrated in Fig. 18 to highlight the development of the mechanical strength (Fig. 18a) and the deposition efficiency DE (Fig. 18b) as a function of the process gas temperature. The $-38+16 \mu \mathrm{m}$ sized $\mathrm{Cu}$ powder was used as the spray material and nitrogen at 30 bars as the process gas. In one set of experiments, at a gas temperature up to $600{ }^{\circ} \mathrm{C}$, the spray particles were injected $20 \mathrm{~mm}$ upstream of the nozzle throat (old standard conditions), and in the other set of experiments, at a gas temperature of $600{ }^{\circ} \mathrm{C}$ and higher, they were injected $135 \mathrm{~mm}$ upstream of the nozzle throat.

The comparison of Fig. 18(a) and (b) demonstrates that first the DE improves steeply with increasing process gas temperature. The mechanical strength of the coatings is only slightly increased until the DE reaches a saturation limit. In this parameter range, the coating strength is dominated by the increasing number of particles that just start to stick. Thus, the fraction of well bonded areas does not increase significantly. After reaching the saturation limit of the DE, the mechanical coating strength rises steeply. Same concepts apply to increasing the impact velocities above critical limits, as shown in
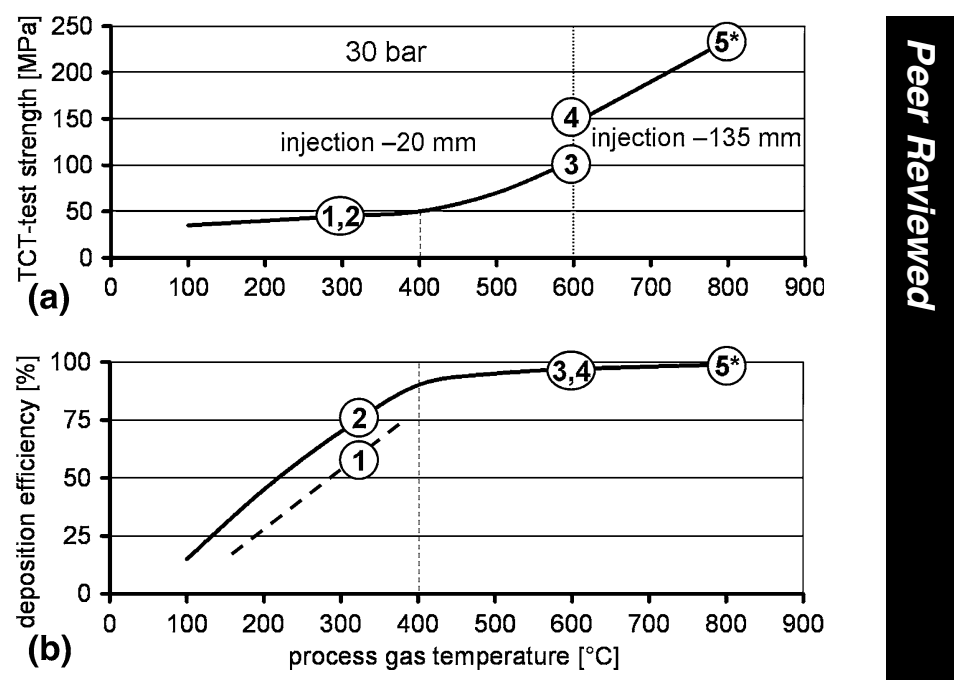

Fig. 18 (a) Coating strength (TCT tests) and (b) DE as a function of the process gas temperature (nitrogen, 30 bars; $-38+16 \mu \mathrm{m} \mathrm{Cu}$ powder from BSA (Ecka) as feedstock). At a gas temperature of $600{ }^{\circ} \mathrm{C}$, the injection point was changed from 20 to $135 \mathrm{~mm}$ in front of the nozzle throat. For parameter sets refer to Table 2. As compared to the standard injection, an early particle injection leads to a jump in the coating strength at a gas temperature of $600{ }^{\circ} \mathrm{C}$, indicating that the particle impact temperature strongly influences particle bonding
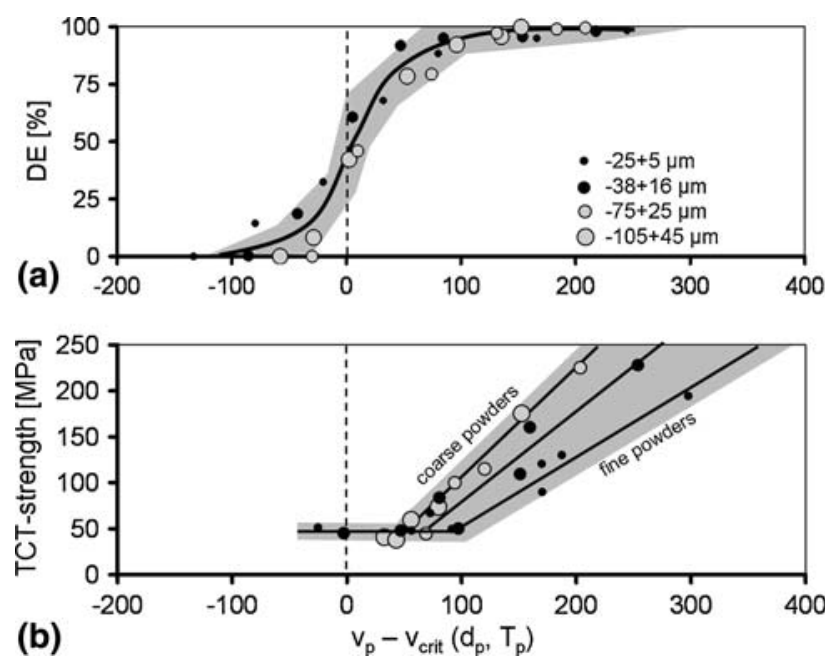

Fig. 19 (a) Coating strength (TCT tests) and (b) DE as a function of the impact velocity

Fig. 19(a) and (b). In parameter ranges above critical limits, every increase in particle impact velocity or particle impact temperature results in a significant increase of the metallurgically bonded areas as indicated in Fig. 20. For a certain spray material, here copper, the window of deposition is defining a parameter range in the temperaturevelocity field, which must be met fairly above the critical limit for bonding. The individual process parameters to meet the requested particle impact conditions are supplied by fluid dynamics.

Figure 21 shows a field of possible hardness and ultimate strength combinations for pure copper coatings (gray 


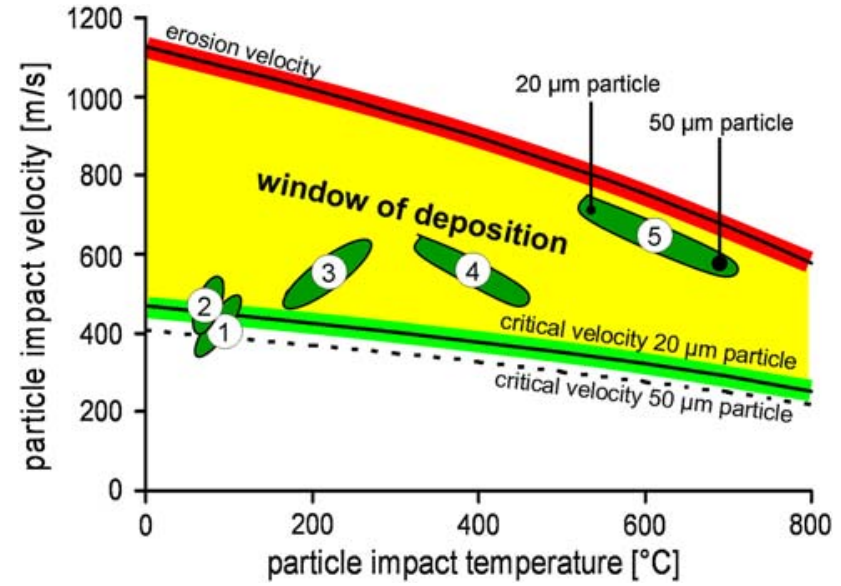

Fig. 20 Window of deposition as function of particle temperature and velocity. Particular impact conditions for copper are also indicated according to process parameters as listed in Table 2

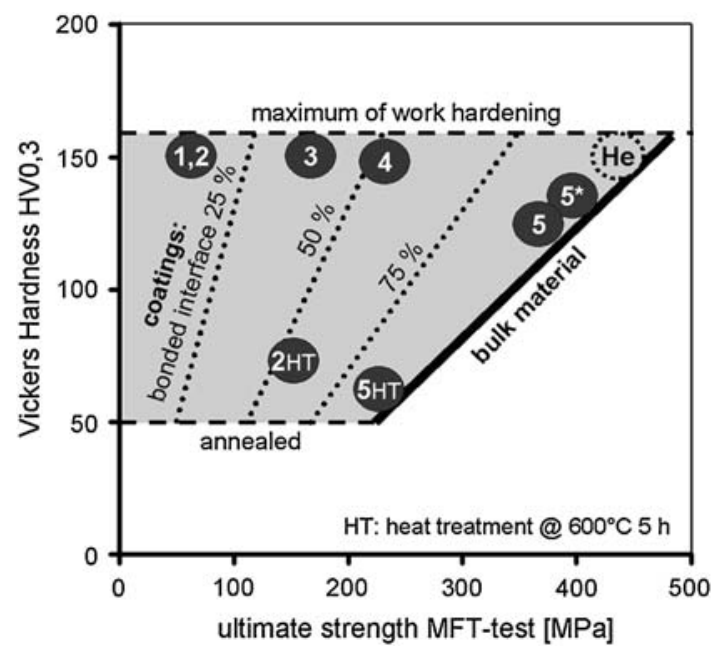

Fig. 21 Hardness vs. ultimate strength for copper bulk material (bold black line) and cold sprayed copper coatings (gray area). Horizontal broken lines indicate minimum and maximum hardness. Diagonal dotted lines correspond to the amount of bonded interface for coatings. The dark circles indicate the properties of the coatings sprayed under the different development steps in as-sprayed and annealed state

area, surrounded by broken and bold black lines). The bold black line represents the linear connection between hardness and ultimate strength for bulk copper. Coating properties very often differ from this linear connection (Ref 13, 14). The way of differing is characteristic for the spray process and the spray conditions. In Fig. 21, the different coating conditions discussed in this study (dark circles with numbers, compare Table 2) are marked.

The hardness of cold sprayed coatings in the as-sprayed state in general is very close to the hardness of highly deformed bulk material (maximum work hardening). Only at the upper limit of spray conditions and using coarse particles the hardness is significantly reduced. However, the amount of bonded interfaces can vary in the range of

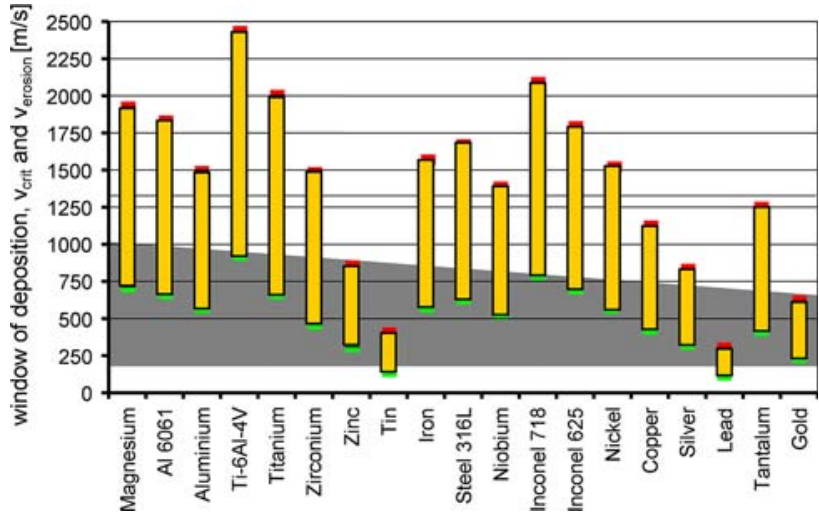

Fig. 22 Calculated critical velocities and windows of deposition for selected metals. The calculations are performed for an impact temperature of $20^{\circ} \mathrm{C}$

15 to $95 \%$. Under conditions spraying with helium as process gas, but also under development step 5 conditions for spraying with nitrogen, the coating properties are very close to those of cold worked bulk material properties. Generally, annealing of the coatings can increase the amount of bonded interfaces, as demonstrated for the development step 2 coating, but such coating will never reach the properties of bulk copper (see condition 2HT), always leaving crack nucleation sites. By spraying with nitrogen as process gas, such bulk-like properties were only achieved by coatings of development step 5 (see condition 5HT).

The results demonstrate that the computation of impact conditions and critical velocities for a particular powder feedstock is the basis of optimizing coating properties. This can be understood on the basis of impact simulations, where excess kinetic energy yields larger fractions of bonded interfaces.

Moreover, the results of this study prove that the generalized parameter window for cold spray deposition in conjunction with the present optimization strategy are powerful tools for further process developments in cold spraying. This knowledge can also be transferred to other ductile spray materials. Figure 22 shows the respective windows of deposition for a range of different materials with a particle size of $25 \mu \mathrm{m}$ and for an impact temperature of $20^{\circ} \mathrm{C}$, calculated with Eq 1 . The marked area indicates the velocity range that is typically accessible using commercial cold spray equipment. While for some materials ideal conditions can easily be met, for others the critical velocity can barely be reached. In the latter cases, the windows of deposition may be shifted toward lower velocities, if the impact temperature is increased and thus the respective flow stress is decreased.

\section{Conclusions}

Comprehensive analyses of cold spraying were performed with computational methods to evaluate the 
bonding mechanisms of the particles on the substrate and to predict the particle temperatures and velocities at the time of impact on the substrate as a function of gas temperature, pressure and nozzle design. Substrate and powder materials and powder feedstock characteristics like size distribution and morphology are additional important parameters and were considered in the modeling and design of cold spraying.

Fluid dynamics calculations yield data for acceleration and heating of different powder feedstock under given process parameters. These data are the basis for further simulations of the impact phenomena, which elucidate the bonding process and coating formation. The simulations show that bonding is due to strong plastic shear deformation at the interfaces between particle and substrate upon impact. Deformation takes place within $50 \mathrm{~ns}$, so that the produced heat cannot be dissipated, leading to highly localized adiabatic shear instabilities. Temperatures in the interface area can be close to the melting point and facilitate bonding. The respective results can be used to predict optimum conditions for bonding. A respective range of impact velocities, the so-called "window of deposition", at a certain initial impact temperature is defined. A distinct excess kinetic energy above the minimum required critical velocity will yield a maximum fraction of bonded interfaces, resulting in maximum strength of the coatings. Moreover, modeling and experiments demonstrate that exceeding critical conditions for bonding can be substantially supported by thermal heat, means higher process gas temperatures. Vice versa, this comprehensive process analysis opens the opportunity to determine optimum coating conditions and give strategic hints for a systematic optimization of the process equipment, including process parameters and nozzle geometry as well as suitable gases or gas mixtures.

Thus, computational process analysis is a powerful tool to attain best coating qualities and to exploit the full potential of cold spraying for the development of new applications.

\section{Acknowledgments}

The Linde Gas AG (Höllriegelskreuth, Germany) and CGT Cold Gas Technology GmbH (Ampfing, Germany) are acknowledged for technical support and collaboration. The authors thank Thomas Breckwoldt, Camilla Kunschke, Dieter Müller, Matthias Schulze, and Uwe Wagener, Helmut Schmidt University, for technical support.

\section{References}

1. A.P. Alkhimov, V.F. Kosarev, and A.N. Papyrin, A Method of Cold Gas-Dynamic Deposition, Sov. Phys. Dokl., 1990, 35(12), p 1047-1049 (Transl: American Institute of Physics, 1991)

2. A.P. Alkhimov, V.F. Kosarev, N.I. Nesterovich, and A.N. Papyrin, Method of Applying Coatings, Russian Patent No. 1618778, September 8, 1990 (Priority of the Invention: June 6,1986)

3. R.C. McCune, A.N. Papyrin, J.N. Hall, W.L. Riggs II, and P.H. Zajchowski, An Exploration of the Cold Gas-Dynamic Spray
Method for Several Material Systems, Advances in Thermal Spray Science and Technology, C.C. Berndt and S. Sampath, Ed., Sept 11-15, 1995 (Houston, TX), ASM International, 1995, p 1-5

4. R.C. Dykhuizen and M.F. Smith, Gas Dynamic Principles of Cold Spray, J. Therm. Spray Technol., 1998, 7, p 205-212

5. A. Papyrin, Cold Spray Technology, Elsevier, Amsterdam, 2007

6. R.G. Maev and V. Leshchynsky, Introduction to Low Pressure Gas Dynamic Spray: Physics \& Technology, Wiley-VCH, Weinheim, 2008

7. V.K. Champagne, The Cold Spray Materials Deposition Process: Fundamentals and Applications, CRC Press, Cambridge, 2007

8. D.L. Gilmore, R.C. Dykhuizen, R.A. Neiser, T.J. Roemer, and M.J. Smith, Particle Velocity and Deposition Efficiency in the Cold Spray Process, J. Therm. Spray Technol., 1999, 8, p 576-582

9. T. Stoltenhoff, H. Kreye, and H.J. Richter, An Analysis of the Cold Spray Process and Its Coatings, J. Therm. Spray Technol., 2002, 11, p 542-550

10. A.P. Alkhimov, S.V. Klinkov, V.F. Kosarev, and A.N. Papyrin, Gas-Dynamic Spraying - Study of a Plane Supersonic Two Phase Jet, J. Appl. Mech. Phys., 1997, 38, p 176-183

11. T. Stoltenhoff, C. Borchers, F. Gaertner, and H. Kreye, Microstructures and Key Properties of Cold-Sprayed and Thermally Sprayed Copper Coatings, Surf. Coat. Technol., 2006, 200, p 4947-4960

12. D. Grasme, First Serial Application of Cold Spraying for Coating Heat Sinks, Proc. 6. Kolloqium Hochgeschwindigkeits - Flammspritzen, P. Heinrich, Ed., Nov 27-28, 2003 (Erding, Germany), Gemeinschaft Thermisches Spritzen e.V., Unterschleißheim, Germany, 2003, p 119-122

13. F. Gaertner, T. Stoltenhoff, J. Voyer, H. Kreye, S. Riekehr, and M. Kocak, Mechanical Properties of Cold-Sprayed and Thermally Sprayed Copper Coatings, Surf. Coat. Technol., 2006, 200, p 6770-6782

14. T. Schmidt, F. Gaertner, H. Kreye, and T. Klassen, Correlation of Particle Impact Conditions and Coating Properties in Cold Spraying, Proceedings of the ITSC 2008 "Thermal Spray Crossing Borders", E. Lugscheider, Ed. (Düsseldorf, Germany), DVSVerlag GmbH, 2008, p 724-731. ISBN 978-3-8715-979-2, on CD

15. T.H. Van Steenkiste, Kinetic Spraying: A new Coating Process, Key Eng. Mater., 2001, 197, p 59-85

16. V.F. Kosarev, S.V. Klinkov, A.P. Alkhimov, and A.N. Papyrin, On Some Aspects of Gas Dynamics of the Cold Spray Process, J. Therm. Spray Technol., 2003, 12, p 265-281

17. M. Grujicic, C.L. Zhao, C. Tong, W.S. DeRosset, and D. Helfritch, Analysis of the Impact Velocity of Powder Particles in the Cold-Gas Dynamic-Spray Process, Mater. Sci. Eng. A, 2003, 368, p 222-230

18. R.C. Dykhuizen, M.F. Smith, D.L. Gilmore, R.A. Neiser, X. Jiang, and S. Sampath, Impact of High Velocity Cold Spray Particles, J. Therm. Spray Technol., 1999, 8, p 559-564

19. H. Assadi, F. Gaertner, T. Stoltenhoff, and H. Kreye, Bonding Mechanism in Cold Gas Spraying, Acta Mater., 2003, 51, p 43794394

20. M. Grujicic, C.L. Zhao, W.S. DeRosset, and D. Helfritch, Adiabatic Shear Instability Based Mechanism for Particles/Substrate Bonding in the Cold-Gad Dynamic-Spray Process, Mater. Des., 2004, 25, p 681-688

21. T. Schmidt, F. Gaertner, H. Assadi, and H. Kreye, Development of a Generalized Parameter Window for Cold Spray Deposition, Acta Mater., 2006, 54, p 729-742

22. Fluent 6.2 User's Guide, Fluent Inc., Lebanon, NH, 2005

23. ABAQUS 6.6. User Manual, ABAQUS, Inc., Providence, RI, 2006

24. T. Stoltenhoff, "Kaltgasspritzen von Kupfer - Eine strömungsmechanische und werkstoffkundliche Analyse und Optimierung des Spritzprozesses," Ph.D. Thesis, Helmut Schmidt University, Hamburg, Germany, 2003, Shaker Verlag, Aachen, Germany, 2004. ISBN 3-8322-2302-9

25. T. Schmidt, "Kaltgasspritzen - Eine Analyse des Materialverhaltens beim Partikelaufprall und die daraus abgeleitete Prozessoptimierung," Ph.D. Thesis, Helmut Schmidt University, Hamburg, Germany, 2007, Shaker Verlag, Aachen, Germany, 2007. ISBN 978-3-8322-6399-7

26. P. Heinrich, H. Kreye, and T. Stoltenhoff, Laval Nozzle for Thermal Spraying and Kinetic Spraying, U.S. Patent No. US 2005/0001075 A1, European Patent No. EP 1506816 A1, 2005 

27. A.P. Alkhimov, A.N. Papyrin, V.F. Kosarev, N.I. Nesterovich, and M.M. Shushpanov, Gas-Dynamic Spray Method for Apply- ing a Coating, U.S. Patent 5,302,414, April 12, 1994
28. T. Schmidt, F. Gaertner, and H. Kreye, New Developments in Cold Spray Based on Higher Gas- and Particle Temperatures, J. Therm. Spray Technol., 2006, 15, p 488-494

29. H.J. Kim, C.H. Lee, and S.Y. Hwang, Fabrication of WC-Co Coatings by Cold Spray Deposition, Surf. Coat. Technol., 2005, 197, p 335-340

30. H.J. Kim, C.H. Lee, and S.Y. Hwang, Superhard Nano WC-12\% Co Coating by Cold Spray Deposition, Mater. Sci. Eng. $A, 2005$, 391, p 243-248 